\title{
Research on Intracranial Atherosclerosis from the East and West: Why Are the Results Different?
}

\author{
Jong S. Kim ${ }^{\mathrm{a}}$, David Bonovich ${ }^{\mathrm{b}}$ \\ ${ }^{a}$ Department of Neurology, Asan Medical Center, University of Ulsan, Seoul, Korea \\ bepartment of Neurology, Sutter Health Eden Medical Center, CA, USA
}

Intracranial atherosclerosis (ICAS) is a major cause of stroke worldwide and is more common in Asians than Caucasians. The study results from the East and West are generally similar, but notable differences exist. For example, studies from the East have reported that ICAS is associated with young age, whereas ICAS seems to be associated with old age in the West. Studies from the East have strongly suggested that mild ICAS associated with branch occlusion is one of the main causes of single subcortical infarction, whereas this aspect has not been considered in stroke classification systems developed in the West. While clopidogrel is commonly used in patients with large artery disease in the West, cilostazol has been more extensively studied and commonly used in ICAS patients in the East. A randomized controlled study from the West reported negative results regarding the efficacy of stenting in ICAS patients due largely to a relatively high rate of periprocedural adverse events, whereas research papers from the East have reported a relatively lower rate of complications. Studies to narrow these East-West gaps should be performed, including risk factor studies using homogenous ethnic populations, studies investigating appropriate classification systems, drug trials in different ethnic populations, and rigorous high standard randomized controlled studies on the efficacy of stenting in Eastern populations.

Keywords Intracranial atherosclerosis; Ethnicities; Risk factors; Antiplatelet; Stenting

\author{
Correspondence: Jong S. Kim \\ Department of Neurology, Asan Medical \\ Center, 86 Asanbyeongwon-gil, Songpa- \\ gu, Seoul 138-736, Korea \\ Tel: $+82-2-3010-3442$ \\ Fax: +82-2-474-4691 \\ E-mail: jongskim@amc.seoul.kr
}

Received: September 9, 2014 Revised: September 10, 2014 Accepted: September 11, 2014

The authors have no financial conflicts of interest.

\section{Introduction}

Intracranial atherosclerosis (ICAS) is a major cause of stroke worldwide, and research on ICAS is therefore increasing. Although ICAS is more prevalent in the Eastern hemisphere than in the Western hemisphere, the study results from both hemispheres are generally similar. For example, studies from both hemispheres have shown that dyslipidemia is less often associated with ICAS than extracranial atherosclerosis (ECAS); however, there are some notable differences in results. For example, while studies from the East have shown that ICAS is more common in younger patients, results from the West have shown that ICAS is more often seen in elderly patients. There is also a dif- ference in drug preference for ICAS treatment. In addition, physicians' understanding of ICAS in terms of the pathogenesis, stroke classification, and stenting efficacy differs between the East and West. In this report, the reasons for these differences between East and West are discussed.

\section{Risk factors}

Many studies investigating ICAS risk factors have been conducted. Some studies have attempted to compare risk factors between ICAS and ECAS. Studies from both the East ${ }^{1-3}$ and the West (subjects with a mixed population of both Caucasians and African Americans $)^{4,5}$ generally agree that dyslipidemia is more 
closely related to ECAS than ICAS. However, there are some differences in the results between the East and West.

In terms of demography, studies from the West ${ }^{6-8}$ have shown that ICAS develops later in life than ECAS. It has been suggested that greater antioxidant enzyme activity in intracranial arteries may contribute to the arteries' improved resistance to atherogenesis, and that decreasing amounts of antioxidants with increasing age may lead to development of ICAS later in life. ${ }^{8}$ On the other hand, studies from the East have generally shown that ICAS is associated with younger age. ${ }^{2,3,9}$ Study results regarding the relationship between ICAS and sex are also conflicting. Large clinical studies from the East have shown that women more often develop ICAS than men ${ }^{2,3,9}$ but one study from China reported that ICAS is more common in men. ${ }^{10}$ In the West, studies with mixed ethnicities ${ }^{5}$ as well as homogeneous Caucasian populations ${ }^{11}$ have reported that women more commonly develop ICAS than men.

Another possible difference between Eastern and Western results regarding ICAS is the role of metabolic syndrome (MetS), a cluster of atherosclerotic risk factors. In the East, it has been shown that MetS is more closely associated with ICAS than with ECAS. ${ }^{2,12,13}$ More recently, MetS has also been found to be associated with ICAS in mixed populations ${ }^{14}$ and Caucasians ${ }^{11}$ suggesting that MetS may be a factor associated with ICAS both in the East and the West. In a study in a multiethnic stroke population, however, MetS and its components were closely associated with ICAS in nonwhites, but associated with ECAS in Caucasians. ${ }^{15}$ Overall, these results suggest that the impact of MetS on development of ICAS may be stronger in Asians than in Caucasians.

This difference is difficult to understand, but it should be remembered that MetS is not a single risk factor; rather, it is a constellation of metabolic factors. The components and the degree of severity of the individual components may differ among ethnicities. ${ }^{16}$ For example, higher rates of obesity and hyperglycemia and lower rates of physical activity are observed in Hispanics than in Caucasians. ${ }^{17}$ Asians have a higher prevalence of hypertension, smoking ${ }^{16}$ and visceral obesity, which is associated with insulin resistance in apparently lean subjects. ${ }^{18}$ Body fat distribution ${ }^{26}$ and the secretion pattern of adiponectin, a protein secreted by adipose tissue, also seem to differ between Caucasians and Asians. ${ }^{19,20}$ These ethnic differences in metabolic derangement profiles may influence the timing and location of atherosclerosis. ${ }^{21}$ For example, the protective effect against oxidative vascular stress may weaken earlier in Asians with these metabolic characteristics, thereby leading to ICAS earlier in life.

A potentially more important explanation for the association of ICAS with young age in the East may be contamination of non-atherosclerotic diseases on ICAS. One of the most important etiologies of contamination seems to be moyamoya disease (MMD). MMD is characterized by bilateral steno-occlusion of the distal internal carotid arteries and proximal middle cerebral arteries with well-developed basal collateral vessels, ${ }^{22}$ although atypical cases such as those with unilateral steno-occlusive disease are occasionally encountered. ${ }^{23,24}$ Moreover, in the early stage of the disease, patients may present with focal middle cerebral artery stenosis without sufficient development of basal collaterals. ${ }^{25} \mathrm{MMD}$ is more prevalent in Asians than in Caucasians and more prevalent in women than in men. ${ }^{26}$ We suspect that the association between young age and ICAS, shown in studies from the East, may be due at least in part to the erroneous inclusion of MMD in ICAS groups.

Another potential confounder may be dissection. Although extracranial dissections (e.g., occurring in arteries such as the internal carotid artery or vertebral artery) are known to be more common than intracranial dissections in the West, ${ }^{27}$ a recent study from the East showed that intracranial artery dissection is more common in Asians. ${ }^{28}$ Methods commonly used for the diagnosis of intracranial arterial disease include computed tomography angiography, magnetic resonance angiography (MRA), or conventional transfemoral angiography. Unless typical features (e.g., dissection flap for dissection and moyamoya collaterals in MMD) are documented, however, it is difficult to correctly assess the pathologic conditions. These imaging modalities are limited to luminal stenosis examination without vascular wall pathology information.

Currently, high-resolution vessel wall MRI (HR-MRI) enables clinicians to assess vessel wall pathology. Atherosclerotic plaque characterization and other pathologies affecting intracranial arteries have been investigated using HR-MRI. ${ }^{29-34} \mathrm{We}$ recently studied 95 young patients ( $\leq 55$ years) with unilateral middle cerebral artery disease ( $\geq 50 \%$ stenosis or occlusion) and who had no or minimal $(\leq 1)$ atherosclerotic risk factors. The initial diagnosis based on MRA was "presumed" atherosclerosis; however, the diagnosis based on HR-MRI findings, were; atherosclerosis in 26, MMD in 29, dissection in 22, and vasculitis in 13 patients (authors' unpublished data). Therefore, atherosclerosis seems to be an uncommon etiology in young patients with minimal vascular risk factors. These results reinforce the problem of erroneous inclusion of nonatherosclerotic vasculopathy in previous ICAS studies. In patients with intracranial stenosis, HR-MRI is a useful differential diagnostic tool.

To correctly diagnose nonatherosclerotic diseases, gene studies may also be useful. One of the best-known examples is the ring finger 213 (RNF 213) gene variation. Patients with this gene variant are highly susceptible to developing MMD; a c.14576G > A 
polymorphism in RNF213 was identified in $95 \%$ of familial MMD patients and in $79 \%$ of sporadic cases. ${ }^{35}$ Identifying this genetic variant will improve our diagnostic ability accordingly, especially when imaging findings are inconclusive for the diagnosis of intracranial steno-occlusion.

The arguments discussed so far, however, should be cautiously interpreted due to differences in study designs between the East and West; while ethnicities are generally homogeneous in Eastern studies, studies from the West usually include heterogeneous ethnicities. Unfortunately, the proportion of different ethnicities is often not described, ${ }^{4,5}$ and risk factor differences between ethnicities are not meticulously examined. Additionally, MRA, computed tomography angiography, or angiography is used in Eastern studies, whereas Doppler ultrasound is more often used in the West, potentially omitting milder ICAS cases.

\section{Stroke mechanism and classification}

Mechanisms leading to stroke or transient ischemic attack include artery-to-artery embolism, local branch occlusion, in situ thrombotic occlusion, and hemodynamic insufficiency. The specific mechanism is reliably assessed with imaging techniques that show topographic patterns of infarction and vascular status, such as diffusion-weighted MRI and MRA. ${ }^{36,37}$ Recent studies on stroke mechanisms in ICAS patients have been performed almost exclusively in the East due mainly to the large number of ICAS patients, but potentially also due to different government reimbursement policies and physician interest.

Although atheromatous branch occlusion was initially addressed by Western physicians. ${ }^{38-41}$ Eastern physicians are currently interested in this issue and have found that a large portion of lacune-like single subcortical infarctions is caused by branch occlusion associated with parental artery atherosclerotic disease. ${ }^{42-47}$ The prevalence of MRA-detected single subcortical infarction associated with ICAS ranges from $17 \%$ to $35 \%$ in the East. ${ }^{44,45}$ It is also seen that the degree of stenosis causing branch occlusion-associated ICAS is generally milder $(<50 \%)$ than that causing artery-to-artery embolism..$^{37,47,48}$ In addition, HRMRI studies have shown that small atherosclerotic plaque, undetectable by conventional MRA, occasionally leads to branch occlusion. ${ }^{49}$ Finally, studies from the East have shown that the diameter of subcortical infarctions caused by branch occlusion varies, and the size criteria may not differentiate the underlying pathogenic mechanism (branch occlusion caused by ICAS versus lipohyalinotic small perforator disease). ${ }^{46}$ Therefore, Eastern physicians tend to believe that ICAS of mild degree should be included with "large artery disease," and that lesion size criteria may not be a reliable method for differentiating large artery disease from small artery disease. ${ }^{50}$

Stroke classification criteria mostly developed in the West have not considered these aspects. The TOAST classification system defined large artery atherosclerosis as corresponding artery stenosis $>50 \%$ and small vessel disease as a subcortical lesion $<15 \mathrm{~mm} .{ }^{51}$ Therefore, stroke associated with a single subcortical infarction $>15 \mathrm{~mm}$ and arterial stenosis $<50 \%$ should be classified as undetermined etiology. In the modified StopStroke Study TOAST classification ${ }^{52}$ the size criteria for small vessel disease were increased from $<15 \mathrm{~mm}$ to $<20 \mathrm{~mm}$. Additionally, embolic infarctions with corresponding stenosis $<50 \%$ accompanied by protruding plaque into the vessel lumen could be classified as large artery atherosclerosis if there was no evidence suggesting other categories. ${ }^{52}$ These criteria and ASCO classification $^{53}$ did not, however, seriously consider single subcortical infarction with mild parental arterial disease.

In response, several Eastern stroke subtyping classifications have been suggested. One study from Korea considered mild $(<50 \%)$ ICAS to be significant arterial disease if the stenosis was located at the index stroke site. ${ }^{54}$ Another Korean study defined atherothrombosis without using criteria limiting the degree of stenosis, but at least one criterion of systemic atherosclerosis was needed to classify the stroke as atherothrombotic. Small artery disease was defined as a single ischemic lesion in a perforating arterial territory, but no strict lesion size criterion was given. ${ }^{55}$ This new classification increased the proportion of large artery atherosclerosis and decreased the proportion of small vessel occlusion. Another new classification called Chinese ischemic stroke subclassification was recently suggested. ${ }^{56}$ In this system, ischemic strokes in the penetrating artery region with any degree of parental artery stenosis were classified as large artery atherosclerosis. The system considered cases with HR-MRIdemonstrated arterial plaque to be large artery atherosclerosis, even absent significant stenosis on MRA. Penetrating artery disease was defined as an isolated infarct in the region of one penetrating artery, regardless of the infarction size. These classification systems from the East share similar concerns in defining ischemic stroke subtypes: 1) lesion size limitation should not be strictly applied for small vessel occlusion and 2) the degree of stenosis of atherosclerotic vessels should not be strictly applied for determining large artery disease subtypes. In conclusion, appropriate stroke classification systems incorporating Eastern stroke characteristics should be developed to narrow the gap between East and West.

\section{Medical treatment}

Aspirin, dipyridamole, and clopidogrel are antiplatelets popu- 
larly used worldwide. Aspirin plus clopidogrel has been the most extensively studied combination therapy. Some trials such as MATCH $,{ }^{57} \mathrm{CHARISMA},{ }^{58}$ and SPS $3{ }^{59}$ have illustrated that combination therapy is no more effective than monotherapy and is associated with significantly increased bleeding risks, especially when used for a prolonged period. Therefore, there is no indication for long-term use of aspirin plus clopidogrel for secondary prevention of stroke. In contrast, other studies from both the West (CARESS) ${ }^{60}$ and the East (CLAIR) ${ }^{61}$ showed that aspirin plus clopidogrel reduced microembolic signals detected by transcranial Doppler to a greater degree than aspirin monotherapy in patients with large artery disease. A recent study in China randomly assigned 5,170 patients with minor stroke or transient ischemic attack to receive either combination or monotherapy and showed that combination therapy (aspirin plus clopidogrel) was significantly more effective than aspirin monotherapy for preventing recurrent strokes when administered early ( $<24$ hours).$^{62}$ The bleeding risks were not different between the two groups. It seems that regardless of ethnicity, the combination of these two drugs may be effective at least in the early stage of stroke, especially in patients with large artery atherosclerosis.

While clopidogrel has been a popular drug for stroke research in the West, Eastern studies have instead focused almost exclusively on cilostazol for the treatment of ischemic stroke. Studies from Japan, ${ }^{63,64}$ Korea, ${ }^{65,66}$ and China ${ }^{67}$ have shown that cilostazol is tolerable and may be superior to aspirin for the secondary prevention of ischemic strokes in Asian patients. There are several reasons for antiplatelet preference differences between Eastern and Western physicians. The first reason can be attributed to regional differences. Clopidogrel is produced by a Western company, whereas cilostazol was developed by a Japanese company. Therefore, regional scientists have an interest in each drug and have better opportunities to receive research funds from their respective companies.

The second reason for preference is scientifically based..$^{68}$ In patients with ECAS, major stroke mechanism is artery-to-artery embolism associated with plaque rupture, platelet aggregation, and generation of thromboembolism. Stroke mechanisms in ICAS, however, are more diverse and include branch occlusion, in situ thrombotic occlusion, and artery-to-artery thromboembolism. ${ }^{2}$ Severe stenosis leading to a cerebral perfusion defect predisposes patients with ICAS to artery-to-artery embolism and in situ thrombotic occlusion. Although perfusion defects are associated with symptomatic events in both ECAS and ICAS patients, progressive vascular occlusion is more devastating in ICAS patients because of the lack of collateral vascular sources such as posterior communicating arteries or extracranial arter- ies. With this in mind, progressive vascular wall narrowing secondary to endothelial injury and smooth muscle proliferation should be prevented in ICAS. Cilostazol inhibits phosphodiesterase and increases cellular levels of cAMP concentrations, which exert diverse actions on the vessel wall. The changed profile has vasodilatory activity, inhibits vascular smooth muscle proliferation, and protects the endothelium. As a result, cilostazol is expected to be effective in patients with ICAS; the TOSS trial was fundamentally based on this assumption. ${ }^{65}$ The positive results from TOSS inspired many studies in the East, ultimately making cilostazol a preferred drug for Asian physicians who encounter ICAS patients more often than their Western counterparts.

Furthermore, cilostazol has minimal bleeding complications. Aspirin plus clopidogrel increases bleeding complications in stroke patients, ${ }^{57}$ especially in patients with lacunar infarction, ${ }^{59}$ which offsets the small advantage of augmented antiplatelet action. In contrast, cilostazol is associated with fewer bleeding complications than aspirin as documented by previous Asian trials. ${ }^{64,67}$ This is another reason for Asian physicians' favorable views of cilostazol.

In terms of ICAS treatment, one study compared aspirin plus cilostazol to aspirin plus clopidogrel and showed that patients receiving aspirin plus cilostazol had a more favorable vascular outcome (less progression and more regression of diseased artery) than those who received aspirin plus clopidogrel..$^{42}$ Nevertheless, aspirin plus clopidogrel was recently used as standard therapy in a large Western trial comparing the optimal medication and stenting in ICAS patients. ${ }^{69}$ This decision may have been made partly because previous studies using aspirin and cilostazol to treat ICAS had relatively small sample sizes and relied on imaging rather than clinical end points, and partly because of regional (East v. West) antiplatelet preferences.

\section{Angioplasty and stenting}

To date, SAMMPRIS is the largest randomized controlled study to compare stenting and medical treatment. The results showed that stenting was associated with high early morbidity and was no more effective than conservative management. ${ }^{69}$ Long-term outcome was equally unfavorable in the stenting group. ${ }^{70}$ Based on this trial, stenting is not considered optimal for treating ICAS. However, a long-standing argument on the results of SAMMPRIS remains. The negative results were primarily associated with early morbidity (stroke, transient ischemic attack), which was as high as $14.7 \%$ in the stenting group. On the other hand, studies from the East have shown lower rates of periprocedural complications and morbidities. ${ }^{71-78}$ Table 1 


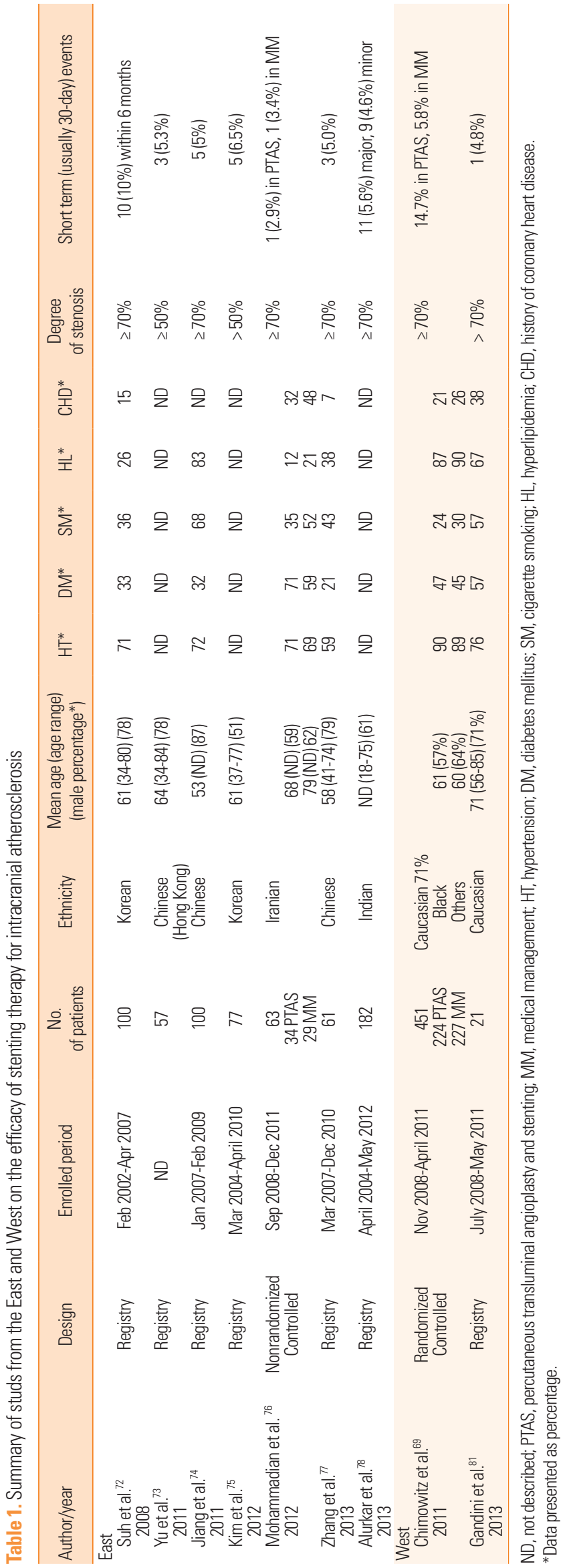

summarizes the clinical studies with more than 20 patients published in English journals that used stenting in ICAS. The discrepancy between the East and West findings may be explained by several reasons.

First, as previously discussed, Western studies have reported that ICAS develops in the later stage of life. As such, ICAS patients in the West may already have atherosclerosis in the proximal vessels such as the aorta or carotid arteries. In this setting, atherothrombotic materials in the proximal vessels may be dislodged more often during the stenting procedure and lead to perioperative adverse events. ${ }^{79}$ Age does not appear to be a factor; the mean age of patients in the SAMMPRIS trial was 61 (stenting group) and 60 (medication group) years old, which was no higher than that in the studies from the East (Table 1). Further supporting this hypothesis, the percentage of patients with diabetes and coronary heart disease markers for vascular atherosclerosis appears to be higher in patients from the West than in those from East Asian countries (Table 1).

Second, interventionists may be less experienced in the West than in the East. The SAMMPRIS authors argued that the high rate of periprocedural complications was not due to inexperience of the operators; ${ }^{69}$ however, the fact that $30 \%(10 / 33)$ of the periprocedural events were due to symptomatic brain hemorrhage has provoked arguments that procedure-related complications due to technical problems may have contributed at least in part to the unfavorable results. ${ }^{80}$ Because ICAS is much more common in the East than in the West, physicians in the East see more patients with hemodynamically unstable ICAS who may need stenting procedures. Moreover, registry studies in Asia are performed in a single large, tertiary center that typically recruits a large number of cases. By analyzing the enrollment period and patient number (Table 1), it is clear that patients enrolled per month ranged from the lowest $(1.05)^{75}$ to the highest $(4)^{74}$ in the East. On the other hand, as many as 50 centers in the USA were involved in SAMMPRIS, and patients enrolled per month per center was only 0.3. Moreover, half of the 451 patients were enrolled from the top 12 enrolling sites and the other half were enrolled by the other 38 sites (personal communication with the PI). Therefore, it is reasonable to assert that at least some of Western investigators were less experienced.

The last, and perhaps the most important reason for the East and West disagreement regarding stenting usefulness, is the possibility that outcome was not sufficiently rigorously assessed in Eastern registry studies. In SAMMPRIS, researchers had a rigorous protocol for evaluating events (e.g., end points evaluated by neurologists, an adjudication process, and site monitoring visits), and the outcome events may have been more precisely captured. In the Asian registry studies, the assessment methods 
(i.e., who assessed the end point using what criteria) were poorly described. Although some argue that events such as stroke or transient ischemic attacks may be hardly unnoticed, they can still be missed unless they are assessed systemically, objectively and, most importantly, independently.

\section{Conclusions and future directions}

Although study results and overarching concepts regarding ICAS are generally similar, there are still notable differences between the East and West. Further studies are recommended, including risk factor studies using homogeneous ethnicities, studies investigating appropriate classification systems that can be applied to patients from the East and West, studies regarding the efficacy of cilostazol in Western patients with ICAS, and more rigorous clinical trials on stenting in the East. Studies using developed imaging techniques or genetic tests should be continued to achieve a more precise diagnosis of intracranial arterial diseases, especially in the East. These studies will help health care professionals better understand the reason for the East-West difference in results, resolve concept differences on ICAS, and develop a better strategy for the diagnosis and management of ICAS, a major cause of stroke worldwide.

\section{References}

1. Uehara T, Tabuchi M, Mori E. Frequency and clinical correlates of occlusive lesions of cerebral arteries in Japanese patients without stroke. Evaluation by MR angiography. Cerebrovasc Dis 1998; 8:267-272.

2. Kim JS, Nah HW, Park SM, Kim SK, Cho KH, Lee J, et al. Risk factors and stroke mechanisms in atherosclerotic stroke: intracranial compared with extracranial and anterior compared with posterior circulation disease. Stroke 2012;43:3313-3318.

3. Kim YD, Choi HY, Jung YH, Nam CM, YangJH, Cho HJ, et al. Classic risk factors for atherosclerosis are not major determinants for location of extracranial or intracranial cerebral atherosclerosis. Neuroepidemiology 2009;32:201-207.

4. Kuller L, Reisler DM. An explanation for variations in distribution of stroke and arteriosclerotic heart disease among populations and racial groups. Am J Epidemiol 1971;93:1-9.

5. Caplan LR, Gorelick PB, Hier DB. Race, sex and occlusive cerebrovascular disease: a review. Stroke 1986;17:648-655.

6. Solberg LA, McGarry PA. Cerebral atherosclerosis in Negroes and Caucasians. Atherosclerosis 1972;16:141-154.

7. Moosy J. Development of cerebral atherosclerosis in various age groups. Neurology 1959;9:569-574.

8. D’Armiento FP, Bianchi A, de Nigris F, Capuzzi DM, D’Armiento
MR, Crimi G, et al. Age-related effects on atherogenesis and scavenger enzymes of intracranial and extracranial arteries in men without classic risk factors for atherosclerosis. Stroke 2001; 32:2472-2479.

9. Lei C, Wu B, Liu M, Chen Y. Risk factors and clinical outcomes associated with intracranial and extracranial atherosclerotic stenosis acute ischemic stroke. J Stroke Cerebrovasc Dis 2013;23: 1112-1117.

10. Huang HW, Guo MH, Lin RJ, Chen YL, Luo Q, Zhang Y, et al. Prevalence and risk factors of middle cerebral artery stenosis in asymptomatic residents in Rongqi County, Guangdong. Cerebrovasc Dis 2007;24:111-115.

11. Lopez-Cancio E, Galan A, Dorado L, Jimenez M, Hernandez M, Millan M, et al. Biological signatures of asymptomatic extra- and intracranial atherosclerosis: the Barcelona-AsIA (Asymptomatic Intracranial Atherosclerosis) study. Stroke 2012; 43:2712-2719.

12. Bang OY, Kim JW, Lee JH, Lee MA, Lee PH, Joo IS, et al. Association of the metabolic syndrome with intracranial atherosclerotic stroke. Neurology 2005;65:296-298.

13. Park JH, Kwon HM, Roh JK. Metabolic syndrome is more associated with intracranial atherosclerosis than extracranial atherosclerosis. Eur J Neurol 2007;14:379-386.

14. Rincon F, Sacco RL, Kranwinkel G, Xu Q, Paik MC, BodenAlbala B, et al. Incidence and risk factors of intracranial atherosclerotic stroke: the Northern Manhattan Stroke Study. Cerebrovasc Dis 2009;28:65-71.

15. Bang OY, Saver JL, Liebeskind DS, Pineda S, Yun SW, Ovbiagele B. Impact of metabolic syndrome on distribution of cervicocephalic atherosclerosis: data from a diverse race-ethnic group. J Neurol Sci 2009;284:40-45.

16. Forouhi NG, Sattar N. CVD risk factors and ethnicity--a homogeneous relationship? Atheroscler Suppl 2006;7:11-19.

17. McGruder HF, Malarcher AM, Antoine TL, Greenlund KJ, Croft JB. Racial and ethnic disparities in cardiovascular risk factors among stroke survivors: United States 1999 to 2001. Stroke 2004;35:1557-1561.

18. Chandalia M, Abate N, Garg A, Stray-Gundersen J, Grundy SM. Relationship between generalized and upper body obesity to insulin resistance in Asian Indian men. J Clin Endocrinol Metab 1999;84:2329-2335.

19. Ford ES. Prevalence of the metabolic syndrome defined by the International Diabetes Federation among adults in the U.S. Diabetes Care 2005;28:2745-2749.

20. Valsamakis G, Chetty R, McTernan PG, Al-Daghri NM, Barnett $\mathrm{AH}$, Kumar $\mathrm{S}$. Fasting serum adiponectin concentration is reduced in Indo-Asian subjects and is related to HDL cholesterol. Diabetes Obes Metab 2003;5:131-135. 
21. Bang OY. Intracranial atherosclerosis: current understanding and perspectives. J Stroke 2014;16:27-35.

22. Suzuki J, Takaku A. Cerebrovascular "moyamoya” disease. Disease showing abnormal net-like vessels in base of brain. Arch Neurol 1969;20:288-299.

23. Kelly ME, Bell-Stephens TE, Marks MP, Do HM, Steinberg GK. Progression of unilateral moyamoya disease: a clinical series. Cerebrovasc Dis 2006;22:109-115.

24. Kuroda S, Hashimoto N, Yoshimoto T, Iwasaki Y. Radiological findings, clinical course, and outcome in asymptomatic moyamoya disease: results of multicenter survey in Japan. Stroke 2007;38:1430-1435.

25. Goyal MS, Hallemeier CL, Zipfel GJ, Rich KM, Grubb RL, Jr., Chicoine MR, et al. Clinical features and outcome in North American adults with idiopathic basal arterial occlusive disease without moyamoya collaterals. Neurosurgery 2010;67:278-285.

26. Wakai K, Tamakoshi A, Ikezaki K, Fukui M, Kawamura T, Aoki $\mathrm{R}$, et al. Epidemiological features of moyamoya disease in Japan: findings from a nationwide survey. Clin Neurol Neurosurg 1997;99:S1-S5.

27. Metso TM, Metso AJ, Salonen O, Haapaniemi E, Putaala J, Artto $\mathrm{V}$, et al. Adult cervicocerebral artery dissection: a single-center study of 301 Finnish patients. Eur J Neurol 2009;16:656-661.

28. Huang YC, Chen YF, Wang YH, Tu YK, Jeng JS, Liu HM. Cervicocranial arterial dissection: experience of 73 patients in a single center. Surg Neurol 2009;72:S20-S27; discussion S7.

29. Klein IF, Lavallee PC, Touboul PJ, Schouman-Claeys E, Amarenco P. In vivo middle cerebral artery plaque imaging by highresolution MRI. Neurology 2006;67:327-329.

30. Ryu CW, Jahng GH, Kim EJ, Choi WS, Yang DM. High resolution wall and lumen MRI of the middle cerebral arteries at 3 tesla. Cerebrovasc Dis 2009;27:433-442.

31. Xu WH, Li ML, Gao S, Ni J, Zhou LX, Yao M, et al. In vivo highresolution MR imaging of symptomatic and asymptomatic middle cerebral artery atherosclerotic stenosis. Atherosclerosis 2010; 212:507-511.

32. Vergouwen MD, Silver FL, Mandell DM, Mikulis DJ, Swartz RH. Eccentric narrowing and enhancement of symptomatic middle cerebral artery stenoses in patients with recent ischemic stroke. Arch Neurol 2011;68:338-342.

33. Degnan AJ, Gallagher G, Teng Z, Lu J, Liu Q, Gillard JH. MR angiography and imaging for the evaluation of middle cerebral artery atherosclerotic disease. AJNR Am J Neuroradiol 2012;33: 1427-1435.

34. Mi Kim S, Ryu CW, Jahng GH, Jong Kim E, Suk Choi W. Two different morphologies of chronic unilateral middle cerebral artery occlusion: evaluation using high-resolution MRI. J Neuroimaging 2014;24:460-466.
35. Fujimura M, Sonobe S, Nishijima Y, Niizuma K, Sakata H, Kure $S$, et al. Genetics and biomarkers of moyamoya disease: significance of RNF213 as a susceptibility gene. J Stroke 2014;16:6572.

36. Wong KS, Gao S, Chan YL, Hansberg T, Lam WW, Droste DW, et al. Mechanisms of acute cerebral infarctions in patients with middle cerebral artery stenosis: a diffusion-weighted imaging and microemboli monitoring study. Ann Neurol 2002;52:7481.

37. Lee DK, Kim JS, Kwon SU, Yoo SH, Kang DW. Lesion patterns and stroke mechanism in atherosclerotic middle cerebral artery disease: early diffusion-weighted imaging study. Stroke 2005; 36:2583-2588.

38. Fisher CM, Caplan LR. Basilar artery branch occlusion: a cause of pontine infarction. Neurology 1971;21:900-905.

39. Lhermitte F, Gautier JC, Derouesne C. Nature of occlusions of the middle cerebral artery. Neurology 1970;20:82-88.

40. Bogousslavsky J, Barnett HJ, Fox AJ, Hachinski VC, Taylor W. Atherosclerotic disease of the middle cerebral artery. Stroke 1986;17:1112-1120.

41. Caplan LR. Intracranial branch atheromatous disease: a neglected, understudied, and underused concept. Neurology 1989;39: 1246-1250.

42. Kwon SU, Hong KS, Kang DW, Park JM, Lee JH, Cho YJ, et al. Efficacy and safety of combination antiplatelet therapies in patients with symptomatic intracranial atherosclerotic stenosis. Stroke 2011;42:2883-2890.

43. Adachi T, Kobayashi S, Yamaguchi S, Okada K. MRI findings of small subcortical "lacunar-like" infarction resulting from large vessel disease. J Neurol 2000;247:280-285.

44. Bang OY, Heo JH, Kim JY, Park JH, Huh K. Middle cerebral artery stenosis is a major clinical determinant in striatocapsular small, deep infarction. Arch Neurol 2002 ;59:259-263.

45. Mok VC, Fan YH, Lam WW, Hui AC, Wong KS. Small subcortical infarct and intracranial large artery disease in Chinese. J Neurol Sci 2003;216:55-59.

46. Cho AH, Kang DW, Kwon SU, Kim JS. Is $15 \mathrm{~mm}$ size criterion for lacunar infarction still valid? A study on strictly subcortical middle cerebral artery territory infarction using diffusion-weighted MRI. Cerebrovasc Dis 2007;23:14-19.

47. Ryoo S, Park JH, Kim SJ, Kim GM, Chung CS, Lee KH, et al. Branch occlusive disease: clinical and magnetic resonance angiography findings. Neurology 2012 20;78:888-896.

48. Kim JS, Yoon Y. Single subcortical infarction associated with parental arterial disease: important yet neglected sub-type of atherothrombotic stroke. Int J Stroke 2013;8:197-203.

49. Yoon Y, Lee DH, Kang DW, Kwon SU, Kim JS. Single subcortical infarction and atherosclerotic plaques in the middle cere- 
bral artery: high-resolution magnetic resonance imaging findings. Stroke 2013;44:2462-2467.

50. Kim BJ, Kim JS. Ischemic stroke subtype classification: an asian viewpoint. J Stroke 2014;16:8-17.

51. Adams HP, Jr., Bendixen BH, Kappelle LJ, Biller J, Love BB, Gordon DL, et al. Classification of subtype of acute ischemic stroke. Definitions for use in a multicenter clinical trial. TOAST. Trial of Org 10172 in Acute Stroke Treatment. Stroke 1993;24: 35-41.

52. Ay H, Furie KL, Singhal A, Smith WS, Sorensen AG, Koroshetz WJ. An evidence-based causative classification system for acute ischemic stroke. Ann Neurol 2005 ;58:688-697.

53. Amarenco P, Bogousslavsky J, Caplan LR, Donnan GA, Hennerici MG. New approach to stroke subtyping: the A-S-C-O (phenotypic) classification of stroke. Cerebrovasc Dis 2009;27:502508 .

54. Kim JT, Yoo SH, Kwon JH, Kwon SU, Kim JS. Subtyping of ischemic stroke based on vascular imaging: analysis of 1,167 acute, consecutive patients. J Clin Neurol 2006 ;2:225-230.

55. Han SW, Kim SH, Lee JY, Chu CK, Yang JH, Shin HY, et al. A new subtype classification of ischemic stroke based on treatment and etiologic mechanism. Eur Neurol 2007;57:96-102.

56. Gao S, Wang YJ, Xu AD, Li YS, Wang DZ. Chinese ischemic stroke subclassification. Front Neurol 2011;2:6.

57. Diener HC, Bogousslavsky J, Brass LM, Cimminiello C, Csiba L, Kaste M, et al. Aspirin and clopidogrel compared with clopidogrel alone after recent ischaemic stroke or transient ischaemic attack in high-risk patients (MATCH): randomised, doubleblind, placebo-controlled trial. Lancet 2004;364:331-337.

58. Bhatt DL, Fox KA, Hacke W, Berger PB, Black HR, Boden WE, et al. Clopidogrel and aspirin versus aspirin alone for the prevention of atherothrombotic events. $N$ Engl J Med 2006;354: 1706-1717.

59. Benavente OR, Hart RG, McClure LA, Szychowski JM, Coffey CS, Pearce LA. Effects of clopidogrel added to aspirin in patients with recent lacunar stroke. N Engl J Med 2012;367:817-825.

60. Markus HS, Droste DW, Kaps M, Larrue V, Lees KR, Siebler $\mathrm{M}$, et al. Dual antiplatelet therapy with clopidogrel and aspirin in symptomatic carotid stenosis evaluated using doppler embolic signal detection: the Clopidogrel and Aspirin for Reduction of Emboli in Symptomatic Carotid Stenosis (CARESS) trial. Circulation 2005;111:2233-2240.

61. Wong KS, Chen C, Fu J, Chang HM, Suwanwela NC, Huang $\mathrm{YN}$, et al. Clopidogrel plus aspirin versus aspirin alone for reducing embolisation in patients with acute symptomatic cerebral or carotid artery stenosis (CLAIR study): a randomised, open-label, blinded-endpoint trial. Lancet Neurol 2010;9:489497.
62. Wang Y, Zhao X, Liu L, Wang D, Wang C, Li H, et al. Clopidogrel with aspirin in acute minor stroke or transient ischemic attack. N Engl J Med 2013;369:11-19.

63. Gotoh F, Tohgi H, Hirai S, Terashi A, Fukuuchi Y, Otomo E, et al. Cilostazol stroke prevention study: a placebo-controlled double-blind trial for secondary prevention of cerebral infarction. J Stroke Cerebrovasc Dis 2000;9:147-157.

64. Shinohara Y, Katayama Y, Uchiyama S, Yamaguchi T, Handa S, Matsuoka K, et al. Cilostazol for prevention of secondary stroke (CSPS 2): an aspirin-controlled, double-blind, randomised noninferiority trial. Lancet Neurol 2010;9:959-968.

65. Kwon SU, Cho YJ, Koo JS, Bae HJ, Lee YS, Hong KS, et al. Cilostazol prevents the progression of the symptomatic intracranial arterial stenosis: the multicenter double-blind placebo-controlled trial of cilostazol in symptomatic intracranial arterial stenosis. Stroke 2005;36:782-786.

66. Lee YS, Bae HJ, Kang DW, Lee SH, Yu K, Park JM, et al. Cilostazol in Acute Ischemic Stroke Treatment (CAIST Trial): a randomized double-blind non-inferiority trial. Cerebrovasc Dis 2011;32:65-71.

67. Huang Y, Cheng Y, Wu J, Li Y, Xu E, Hong Z, et al. Cilostazol as an alternative to aspirin after ischaemic stroke: a randomised, double-blind, pilot study. Lancet Neurol 2008; 7:494-499.

68. Kim JS, Shinohara Y. Cilostazol: a drug particularly effective for Asians? Int J Stroke 2011;6:209-210.

69. Chimowitz MI, Lynn MJ, Derdeyn CP, Turan TN, Fiorella D, Lane BF, et al. Stenting versus aggressive medical therapy for intracranial arterial stenosis. N Engl J Med 2011;365:993-1003.

70. Derdeyn CP, Chimowitz MI, Lynn MJ, Fiorella D, Turan TN, Janis LS, et al. Aggressive medical treatment with or without stenting in high-risk patients with intracranial artery stenosis (SAMMPRIS): the final results of a randomised trial. Lancet 2014;383:333-341.

71. Liu JM, Hong B, Huang QH, Xu Y, Zhao WY, Zhang L, et al. [Safety and short-term results of stent-assisted angioplasty for the treatment of intracranial arterial stenosis]. Zhonghua Wai Ke Za Zhi 2004;42:169-172.

72. Suh DC, Kim JK, Choi JW, Choi BS, Pyun HW, Choi YJ, et al. Intracranial stenting of severe symptomatic intracranial stenosis: results of 100 consecutive patients. AJNR Am J Neuroradiol 2008;29:781-785.

73. Yu SC, Leung TW, Lee KT, Hui JW, Wong LK. Angioplasty and stenting of atherosclerotic middle cerebral arteries with Wingspan: evaluation of clinical outcome, restenosis, and procedure outcome. AJNR Am J Neuroradiol 2011;32:753-758.

74. Jiang WJ, Yu W, Du B, Gao F, Cui LY. Outcome of patients with $\geq 70 \%$ symptomatic intracranial stenosis after Wingspan stenting. Stroke 2011;42:1971-1975. 
75. Kim KS, Hwang DH, Ko YH, Kang IW, Lee ES, Han YM, et al. Usefulness of stent implantation for treatment of intracranial atherosclerotic stenoses. Neurointervention 2012;7:27-33.

76. Mohammadian R, Pashapour A, Sharifipour E, Mansourizadeh R, Mohammadian F, Taher Aghdam AA, et al. A comparison of stent implant versus medical treatment for severe symptomatic intracranial stenosis: a controlled clinical trial. Cerebrovasc Dis Extra 2012;2:108-120.

77. Zhang L, Huang Q, Zhang Y, Deng B, Liu J, Hong B, et al. A single-center study of Wingspan stents for symptomatic atherosclerotic stenosis of the middle cerebral artery. J Clin Neurosci 2013;20:362-366.

78. Alurkar A, Karanam LS, Oak S, Nayak S, Sorte S. Role of balloon-expandable stents in intracranial atherosclerotic disease in a series of 182 patients. Stroke 2013;44:2000-2003.
79. Cho AH, Cho YP, Lee DH, Kwon TW, Kwon SU, Suh DC, et al. Reperfusion injury on magnetic resonance imaging after carotid revascularization. Stroke 2014;45:602-604.

80. Yu SC, Cheng HK, Cheng PW, Lui WM, Leung KM, Tan CB, et al. Angioplasty and stenting for intracranial atherosclerotic stenosis: position statement of the Hong Kong Society of Interventional and Therapeutic Neuroradiology. Hong Kong Med J2013;19:69-73.

81. Gandini R, Chiaravalloti A, Pampana E, Massari F, Morosetti $\mathrm{D}$, Spano $\mathrm{S}$, et al. Intracranial atheromatous disease treatment with the Wingspan stent system: evaluation of clinical, procedural outcome and restenosis rate in a single-center series of 21 consecutive patients with acute and mid-term results. Clin Neurol Neurosurg 2013; 115:741-747. 